\title{
Avaliação de argamassas colantes por reometria rotacional
}

\author{
Evaluation of adhesive mortars by rotational rheometry
}

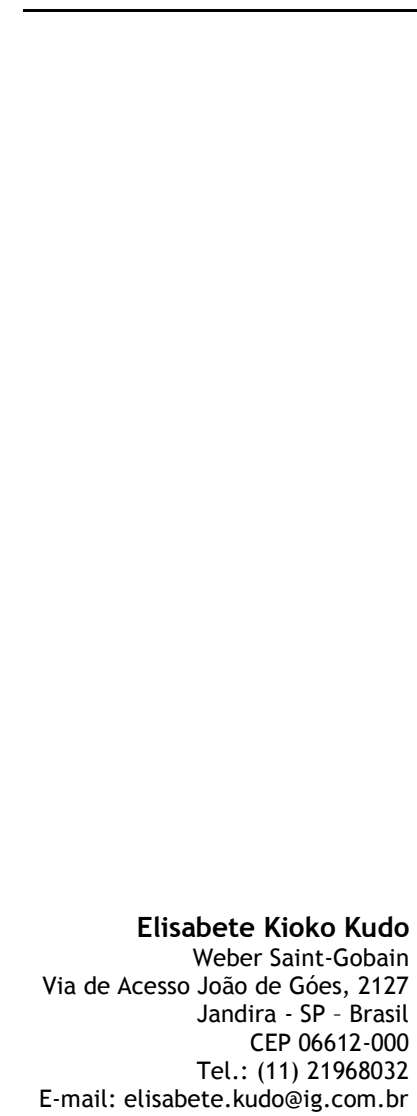

Elisabete Kioko Kudo
Fábio Alonso Cardoso
Rafael Giuliano Pileggi

Resumo

A

s argamassas colantes são produtos constituídos por areia natural ou artificial, ligantes (cimento) e aditivos químicos que cumprem uma função de adesivo para assentamento de revestimentos em pisos e paredes. Atualmente, a avaliação em campo sobre a mistura do produto é efetuada de forma empírica. $\mathrm{O}$ aplicador (pedreiro) determina, por meios de aspectos sensoriais, a facilidade ou a dificuldade de mistura, classificando a argamassa em pesada, leve, macia, de fácil ou de difícil mistura, etc. Porém, essas descrições são subjetivas e é difícil de mensurar quantitativamente a aplicabilidade do produto, além do que induzem a erros de avaliação, pois cada aplicador pode ter uma percepção diferente. O propósito deste trabalho foi medir, através da reometria rotacional, duas composições para avaliar o comportamento de mistura e reológico de forma quantitativa. Foram utilizadas duas argamassas colantes de mercado do tipo ACI (Argamassa Colante do Tipo I) e ACIII (Argamassa Colante do Tipo III), as quais foram submetidas a ensaios de reometria rotacional, variando-se o teor de água. Os resultados desta pesquisa demonstram que o tempo de mistura de $150 \mathrm{~s}$ é eficiente e suficiente para homogeneizar e estabilizar as argamassas testadas, e que a argamassa do tipo ACI apresenta maior dificuldade de mistura e resulta em uma suspensão com maior viscosidade e tensão de escoamento do que a argamassa ACIII. Este estudo mostra a aplicação e os resultados inéditos de reometria rotacional para avaliação do comportamento reológico de argamassas colantes. Essa transferência do conhecimento visa ampliar os horizontes sobre os comportamentos dos materiais de construção civil para melhorar o desempenho de aplicação e avaliação da argamassa no estado fresco.

Fábio Alonso Cardoso Departamento de Engenharia de Construção Civil, Escola Politécnica Universidade de São Paulo Av. Prof. Almeida Prado, trav.2, n.

83, Cidade Universitária, Butantã São Paulo - SP - Brasil CEP 05508-900 Tel.: (11) 3091-5248

E-mail: fabio.cardoso@lme.pcc.usp.br

Rafael Giuliano Pileggi Departamento de Engenharia de Construção Civil, Escola Politécnica

Universidade de São Paulo Av. Prof. Almeida Prado, trav.2, n.

83, Cidade Universitária, Butantã São Paulo - SP - Brasil CEP 05508-900 Tel.: (11) 3091-5442

E-mail: rafael.pileggi@poli.usp.br

Recebido em 27/06/12

Aceito em 17/04/13

Palavras-chave: Reometria de mistura. Reometria rotacional. Caracterização reológica. Argamassa colante.

\section{Abstract}

Adhesive mortars are products consisting of natural or artificial sand, binder (cement) and chemical additives, which serve as adhesives for laying floor and wall tiles. Nowadays, the field evaluation of the product mixture is made empirically. The worker (plasterer) determines, by means of sensory aspects, the ease of mixing, classifying the mortar into heavy, light, soft, easy or difficult to mix. However, these descriptions are subjective and it is not easy to measure quantitatively the applicability of the product, and this may also lead to judgment errors, because each worker may have a different perception. The aim of this study is to evaluate two adhesive mortars by rotational rheometry. Adhesive mortars types ACI and ACIII, with different water contents, were submitted to rotational rheometry tests in order to evaluate both mixing and flow behavior. The results indicate that the mixing time of $150 \mathrm{~s}$ was enough to effectively homogenize and disperse the mortars. The mixing and flow torque values are higher for ACI than for ACIII, indicating that ACI is more difficult to mix and has higher viscosity than ACIII.

Keywords: Rotational rheometry. Rheological characterization. Adhesive mortar.

Ambiente Construído, Porto Alegre, v. 13, n. 2, p. 125-137, abr./jun. 2013. 


\section{Introdução}

As argamassas colantes, de acordo com a norma vigente NBR 14081-1 (ABNT, 2012), podem ser classificadas em ACI, ACII, ACIII e as do tipo E.

Geralmente, a argamassa do tipo ACI é recomendada para utilização em ambientes internos, para aplicação e exposição em ambiente sem ação de intempéries, nem solicitações de aderência de alto desempenho ou altas temperaturas $\left(>70^{\circ} \mathrm{C}\right)$, aplicada para aderir peças de revestimentos com absorção de água superior a $0,5 \%$. São utilizados em sua formulação éteres de celulose MHEC (metil-hidroxietil-celulose) e/ou MHPC (metil-hidroxipropil-celulose), como aditivos que promovem a retenção de água, aumentam a viscosidade e contribuem na resistência de aderência (OHAMA, 1998; BETIOLI, 2007; PÓVOAS, 2005; PATURAL et al., 2010).

Já a argamassa do tipo ACIII é utilizada em ambientes externos, fachadas de edifícios, locais expostos a intempéries e com altas temperaturas, como saunas e piscinas aquecidas, aplicada para aderir peças cerâmicas com baixa absorção de água, $<0,5 \%$, que demandem alto desempenho de adesão e flexibilidade, exigindo a necessidade de adição de polímeros vinílicos, acrílicos (EVA/PVA), entre outros, que promovam a melhoria do desempenho.

O comportamento reológico é importante, porque, quando o produto apresenta um comportamento reológico inadequado, o profissional (assentador) pode reduzir ou aumentar empiricamente a quantidade de água adicionada na argamassa para ajustar a aplicação ou facilitar a mistura, porém esses acertos são apenas paliativos.

No caso da redução da água, haveria uma secagem muito rápida da argamassa, o que afetaria a interação entre argamassa fresca e substrato, causando defeito no desenvolvimento da microestrutura da argamassa e afetando as propriedades no estado endurecido (ANTUNES; JOHN; PILEGGI, 2005).

Já o aumento da relação água-cimento causa um afastamento das partículas de cimento, dificultando a consolidação (o gel de CSH forma-se entre as partículas de cimento, consolidando-as). Além disso, a água em excesso não utilizada nas reações de hidratação é expulsa, o que cria pontos de fragilidade.

Nesse contexto, este trabalho propõe a utilização do método de reometria rotacional para avaliação das argamassas colantes. Através da reometria rotacional, pode-se avaliar o comportamento de fluxo de fluidos e suspensões em uma ampla faixa de taxas de cisalhamento, permitindo determinar o torque de escoamento, nível de torque e inclinação que indica a viscosidade plástica (tensão de cisalhamento/taxa de cisalhamento), contribuindo, assim, no controle e desenvolvimento de produtos cimentícios. Essas propriedades podem ser determinadas por meio da aplicação de cisalhamento de forma controlada, medindo-se o torque necessário.

Utilizando o mesmo princípio, pode-se identificar a cinética de mistura das argamassas, de maneira a quantificar a facilidade de mistura de uma composição e, também, identificar a ação de aditivos que mudem a resistência ao fluxo do sistema. A técnica é denominada reometria de mistura e requer que o reômetro tenha potência e geometria (recipiente + raquete formada por 6 haletas) adequadas para tal finalidade.

Diversos pesquisadores (ROMANO et al., 2007; CARDOSO, 2009; FRANÇA; CARDOSO; PILEGGI, 2011) utilizaram o método de reometria com taxa de cisalhamento controlada (Poli-USP), desenvolvido pelo Prof. Dr. Rafael G. Pillegi, tanto para avaliação do processo de mistura de argamassas de revestimentos, quanto para a avaliação do comportamento reológico pela aplicação de ciclos de cisalhamento. Porém, para argamassas colantes, o método não foi totalmente explorado.

Dessa forma, o objetivo deste trabalho é utilizar a reometria rotacional para avaliar a cinética de mistura e o comportamento reológico das argamassas colantes de mercado dos tipos ACI e ACIII.

\section{Reometria rotacional}

\section{Mistura: dispersão e distribuição}

As propriedades finais de uma argamassa são fortemente afetadas pela qualidade da mistura, que pode ser dividida em dois fenômenos principais: a dispersão e a distribuição (COLLIN; JÉZÉQUEL, 2009).

A dispersão é a quebra dos aglomerados de partículas geralmente formadas nos primeiros momentos após a adição de água. A distribuição está diretamente relacionada com a homogeneidade do produto final, correspondendo à capacidade do misturador de espalhar as partículas no interior da composição.

$\mathrm{O}$ processo de mistura inicia-se com a introdução do líquido. O líquido causa uma série de eventos

126 Kudo, E. K.; Cardoso, F. A.; Pileggi, R. G. 
de aglomeração e de desaglomeração, ou seja, o material tende a agrupar-se e, depois, dispersar-se, gerando esforços resultantes (PILLEGI; STUDART; PANDOLFELLI, 2001).

As partículas com grandes áreas superficiais, em geral, tendem a agrupar-se (aglomeração), e duas forças passam a atuar: as de Van der Waals e as capilares (PILLEGI; STUDART; PANDOLFELLI, 2001; COLLIN; JÉZÉQUEL, 2009). Porém, quando o cisalhamento é aplicado durante a mistura, esses aglomerados dispersamse, facilitando, assim, a homogeneização da mistura (PILLEGI; STUDART; PANDOLFELLI, 2001).

Segundo Romano et al. (2007), essa aglomeração é responsável pela retenção de parte da água necessária para realizar a homogeneização, sendo que, se a mistura não for suficiente para destruir esses aglomerados, a água ficará indisponível para hidratar as partículas de cimentos e, portanto, fluidificar a mistura.

Já a homogeneização eficaz da mistura está relacionada com fatores como o tipo de misturador, o tempo de mistura (ROMANO et al., 2007, COLLIN; JÉZÉQUEL, 2009), o desenho interno do misturador (haletas, pás), o volume de material, a velocidade aplicada e o teor de água adicionada (COLLIN; JÉZÉQUEL, 2009).

A avaliação do comportamento de mistura é importante, devido a esta ser a principal etapa do processamento das argamassas e ter influência, principalmente, sobre o consumo de água e comportamento reológico, podendo, assim, afetar a facilidade de aplicação do produto.

França, Cardoso e Pileggi (2011), por meio de avaliação da influência do tempo de mistura nas propriedades reológicas de argamassas de revestimento, constataram que o comportamento reológico de uma argamassa desse tipo é significativamente influenciada pelo tempo de mistura, pois, em tempos de mistura curtos, observou-se o não rompimento dos aglomerados formados após a adição da água. Esse cenário resultou em materiais reologicamente instáveis e menos fluidos, e demandou, assim, o aumento do tempo de mistura para que a argamassa ficasse homogênea.

Outro fator relevante na mistura é a sequência da introdução dos materiais. Antunes, John e Pileggi (2005) avaliaram a influência da sequência de mistura nas propriedades reológicas de argamassas de revestimento e concluíram que a sequência de introdução de água no pó apresentava menor variabilidade no comportamento reológico. Isso porque essa sequência faz com que os componentes dispersem-se melhor, aumentando a eficiência do processo, reduzindo a viscosidade da argamassa, melhorando $\mathrm{o}$ espalhamento $\mathrm{e}$, consequentemente, a aderência.

\section{Comportamento reológico}

A reometria rotacional avalia as propriedades reológicas dos fluidos (VAN DEN BRULE; KADIJK, 1992; WINTHER; LARSSON; KRAMER, 1991; MALKIN, 1994; STEFFE, 1996), determina características como tensão de escoamento, viscosidade, histerese, inclinação de curvas e níveis de torque, pela aplicação de diferentes taxas de cisalhamento ao fluido, e medição do esforço (torque ou tensão de cisalhamento) resultante (CARDOSO, 2009).

As propriedades de fluxo de argamassa, para estar em conformidade com o modelo de Bingham, requerem dois parâmetros: o limite de escoamento e a viscosidade plástica. Estes, por sua vez, são afetados diretamente pela origem dos insumos, como cimento, areia, água e aditivos adicionados na mistura (BANFILL; SAUNDERS, 1981).

A tensão de escoamento é obtida por meio da reometria rotacional, nível de torque mínimo para que o material comece a escoar. Essa tensão mínima de cisalhamento, denominada tensão de escoamento, pode ser originada pela aglomeração das partículas do fluido, de modo a formar uma estrutura espacial rígida de partículas por toda a suspensão. A tensão de escoamento das suspensões corresponde à tensão necessária para romper essa estrutura tridimensional das partículas (SCHRAMM, 2006; OLIVEIRA et al., 2000; BARNES, 1998).

Já a viscosidade aparente pode ser extraída a partir da curva de aplicação de taxa de cisalhamento. A viscosidade é um indicativo de coesão entre as moléculas que consiste nas lâminas adjacentes do fluido (OLIVEIRA et al., 2000; MALKIN, 1994; STEFFE, 1996). Essa característica também pode indicar a facilidade de um material escoar continuamente sob a ação de uma tensão de cisalhamento externa. Quanto menor for a viscosidade de um fluido, menor será a tensão necessária para impor uma taxa de velocidade constante. A viscosidade pode ser calculada pela relação entre a tensão e a taxa de cisalhamento (BANFILL; SAUNDERS, 1981; MALKIN, 1994; STEFFE, 1996; OLIVEIRA et al., 2000), de acordo com a Equação 1.

$\tau=\eta \cdot \gamma$

Eq. 1

Onde:

$\tau=$ tensão de cisalhamento; 
$\eta=$ viscosidade $; e$

$\gamma=$ taxa de cisalhamento.

Os materiais que apresentam pseudoplasticidade ou dilatância com tensão de escoamento são denominados fluidos de Bingham. Nestes, a pseudoplasticidade ocorre quando a viscosidade da suspensão diminui com o aumento da taxa (ou tensão) de cisalhamento, e a dilatância ocorre quando a viscosidade da suspensão aumenta com o aumento da taxa (ou tensão) de cisalhamento (OLIVEIRA et al., 2000, MALKIN, 1994; STEFFE, 1996).

A histerese é a diferença entre os resultados das curvas de aceleração e desaceleração nos ciclos de cisalhamento, e pode ser utilizada para avaliar a condição de mistura de uma argamassa. Segundo Schramm (2006), a área de histerese é proporcional à energia necessária para quebrar a estrutura de aglomerados formada quando o processo de mistura inicial não é suficientemente eficiente. Mesmo após a aplicação de um ciclo de cisalhamento, a quebra total da estrutura pode não ocorrer, sendo necessária a aplicação de outros ciclos, até que as curvas sobreponham-se, indicando que toda a estrutura foi destruída pelo cisalhamento.

Banfill e Saunders (1981) avaliaram o comportamento reológico de diferentes pastas de cimento, por meio de curvas de histerese, e concluíram que a diferença encontrada nas curvas era dada principalmente pela condição de mistura, pelo tipo de cimento, pelo aditivo químico adicionado e pela taxa de cisalhamento imposta ao material.

Dessa forma, as informações extraídas, tanto no processo de mistura como no processo de aplicação de ciclos de cisalhamento, contribuem para o dimensionamento e o desenvolvimento de produtos que apresentem energias de mistura que proporcionem facilidade de mistura e produtividade.

\section{Materiais e métodos}

A metodologia e os equipamentos utilizados neste trabalho foram desenvolvidos por pesquisadores da Poli-USP, tendo sido somente os tempos de mistura e os patamares adaptados para aplicação nas argamassas colantes.

Para a avaliação do comportamento reológico, utilizando a mesma argamassa que foi misturada, aplicaram-se taxas de cisalhamento entre períodos de acréscimo e decréscimo (ciclos de cisalhamento), em que é possível obter-se uma curva de subida e de descida para avaliação da viscosidade plástica, nível de torque, tensão de escoamento e histerese.

\section{Argamassas}

Foram selecionadas e homogeneizadas em laboratório duas amostras de $300 \mathrm{~kg}$ de argamassas de mercado: ACI (Argamassa Colante do Tipo I) e ACIII (Argamassa Colante do Tipo III).

Neste estudo, para a argamassa ACI foram utilizados os teores de água de 19,4\%, 21,5\% e $23,7 \%$, sendo $21,5 \%$ o teor de água nominal especificado pelo fabricante. Para a argamassa ACIII foram utilizados os teores de água de $28,8 \%$, $32,0 \%$ e $35,2 \%$, sendo $32,0 \%$ o teor de água nominal especificado pelo fabricante.

Esses teores de água especificados pelo fabricante são baseados no desempenho em obra e em laboratório. Em campo, a argamassa deve cumprir o desafio de apresentar boa aplicabilidade, tempo suficiente para espalhamento na base e para o assentamento de peças de revestimento cerâmico, e boa adesividade a fresco, para que a peça não se mova durante o assentamento. Em laboratório, deve cumprir os requisitos de desempenho no estado endurecido preconizados na norma vigente NBR14081-1 (ABNT, 2012).

Considerando que o fabricante tenha cumprido essas etapas de determinação do teor de água de aplicação, este trabalho adota os dois teores de água especificados pelo fabricante e as variações deste teor que geralmente são empregadas para cobrir as flutuações de processo de fabricação.

Cada argamassa foi caracterizada em estado anidro, com o objetivo de verificar as diferenças entre elas. Para tanto, foram utilizados os seguintes ensaios.

(a) determinação dos teores de finos e agregados: 2 amostras de $300 \mathrm{~g}$ de material foram peneiradas em malha $200(75 \mu \mathrm{m})$ por $30 \mathrm{~min}$ em peneirador automático do tipo "Ro-Tap". Os materiais passantes (finos $<75 \mu \mathrm{m}$ ) e retidos (agregados > $75 \mu \mathrm{m})$ foram pesados;

(b) distribuição granulométrica: foi utilizado um granulômetro a laser (Malvern MSS Mastersizer). Os finos foram dispersos em álcool, enquanto os agregados mais grossos foram ensaiados dispersos em ar, para a realização do ensaio;

(c) massa específica: foi determinada através do picnômetro de gás hélio (MultiPycnometer, Quantachrome Instruments); e

(d) superfície específica: foi determinada por meio da adsorção de gases, utilizando a técnica de BET (Brunauer, Emmett, Teller) e gás nitrogênio (Micromeritics ASAP 2010). 
A Tabela 1 mostra os resultados das caracterizações.

Para a argamassa ACI, a porcentagem de agregados é superior quando comparada à ACIII. Consequentemente, o teor de finos (partículas $<75$ $\mu \mathrm{m}$ da areia + aditivos + cimento) é superior na argamassa ACIII.

A Figura 1 mostra as distribuições granulométricas das argamassas ACI e ACIII.

Os resultados de granulometria confirmam os dados da Figura 1, onde a proporção de finos (partículas $<75 \mu \mathrm{m}$ da areia + aditivos + cimento) $<100 \mu \mathrm{m}$ é maior na ACIII do que na ACI, sendo $1 \mathrm{~mm}$ o tamanho máximo da areia determinado por granulômetro a laser.

\section{Mistura}

Utilizou-se um reômetro rotacional da Poli-USP para a caracterização do comportamento de mistura e da natureza reológica de argamassas. Os ensaios foram realizados com a geometria de ensaio acoplada ao dispositivo rotacional, onde são medidos os valores de torque necessários para girar a raquete. Todas as operações de controle operacional e dados foram coletados e armazenados no software de controle do equipamento (Figura 2).

Para a análise da cinética da mistura, foram utilizadas bateladas de $4 \mathrm{~kg}$ de material anidro, submetidos à mistura por $300 \mathrm{~s}$ em rotação constante $(126,5 \mathrm{rpm})$, com a adição controlada de água (vazão constante de $125 \mathrm{~g} / \mathrm{s}$ ) a partir de $30 \mathrm{~s}$. Após a mistura, o produto ficou por mais $15 \mathrm{~min}$ em rotação dez vezes menor (12,7 rpm), para maturação e ação dos aditivos. Após a maturação, determinou-se o teor de ar incorporado. A Figura 3 indica o programa de mistura utilizado.

Tabela 1 - Caracterização física das argamassas da ACl e ACIII

\begin{tabular}{l|c|c|c|c|c|c|c}
\hline $\begin{array}{c}\text { Tipo de } \\
\text { argamassa }\end{array}$ & $\begin{array}{c}\text { Agreg } \\
(\boldsymbol{\%})\end{array}$ & $\begin{array}{c}\text { Finos } \\
(\boldsymbol{\%})\end{array}$ & $\begin{array}{c}\boldsymbol{\rho} \mathbf{A g r e g} \\
\left(\mathbf{g} / \mathbf{c m}^{3}\right)\end{array}$ & $\begin{array}{c}\rho \text { Finos } \\
\left(\mathbf{g} / \mathbf{c m}^{3}\right)\end{array}$ & $\begin{array}{c}\rho A r g \\
\left(\mathbf{g} / \mathbf{c m}^{\mathbf{3}}\right)\end{array}$ & $\begin{array}{c}\text { ASFinos } \\
\left(\mathbf{m}^{2} / \mathbf{g}\right)\end{array}$ & $\begin{array}{c}\text { Rel. a/ms } \\
(\boldsymbol{\%})\end{array}$ \\
\hline ACI & 76,4 & 23,6 & 2,64 & 2,99 & 2,73 & 1,51 & $21,5^{*}$ \\
ACIII & 52,2 & 47,8 & 2,63 & 3,02 & 2,75 & 1,36 & $32,0^{*}$ \\
\hline
\end{tabular}

Nota: Legenda:
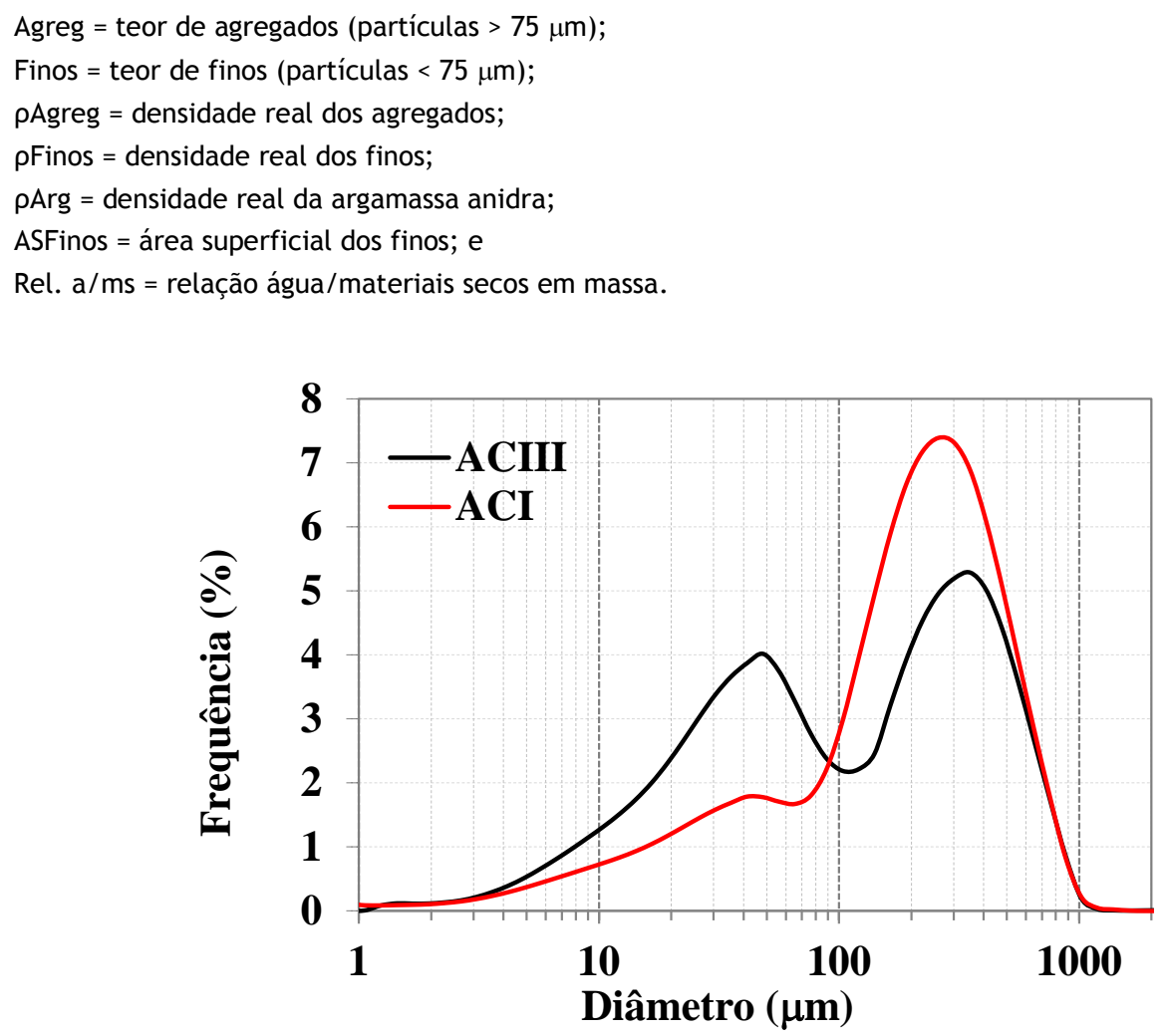

Figura 1 - Curvas granulométricas das argamassas ACl e ACIII, obtidas através de granulômetro a laser (Malvern MSS Mastersizer) 


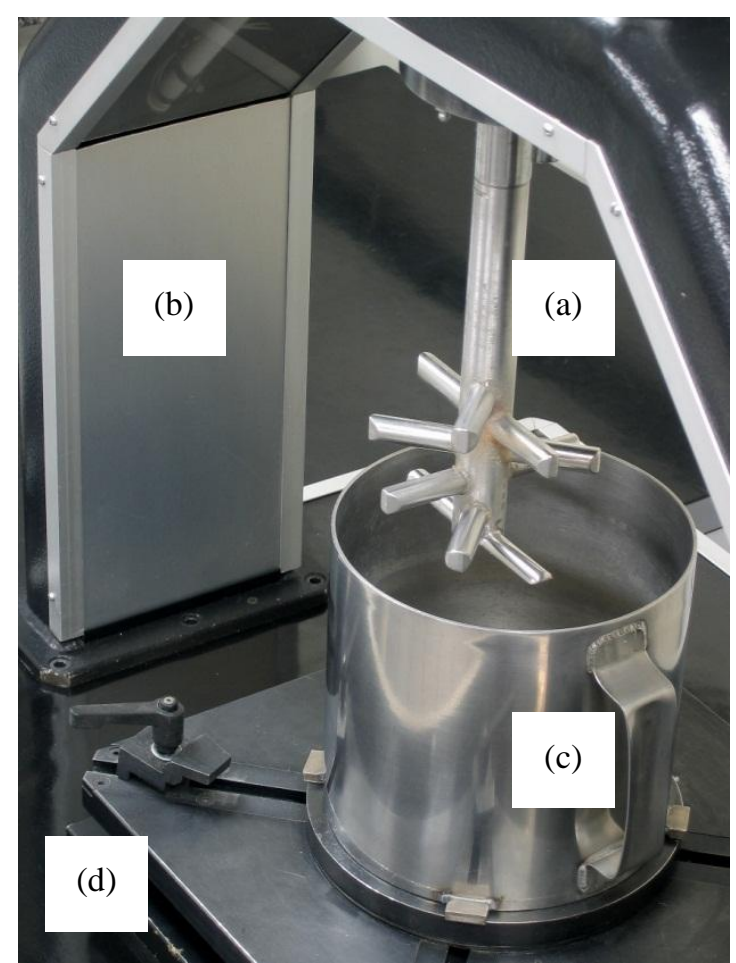

Figura 2 - Reômetro: (a) geometria de mistura (raquete) composta de haletas radiais montadas em espiral (6 haletas); (b) estrutura de sustentação do motor; (c) recipiente de ensaio; e (d) base de reação

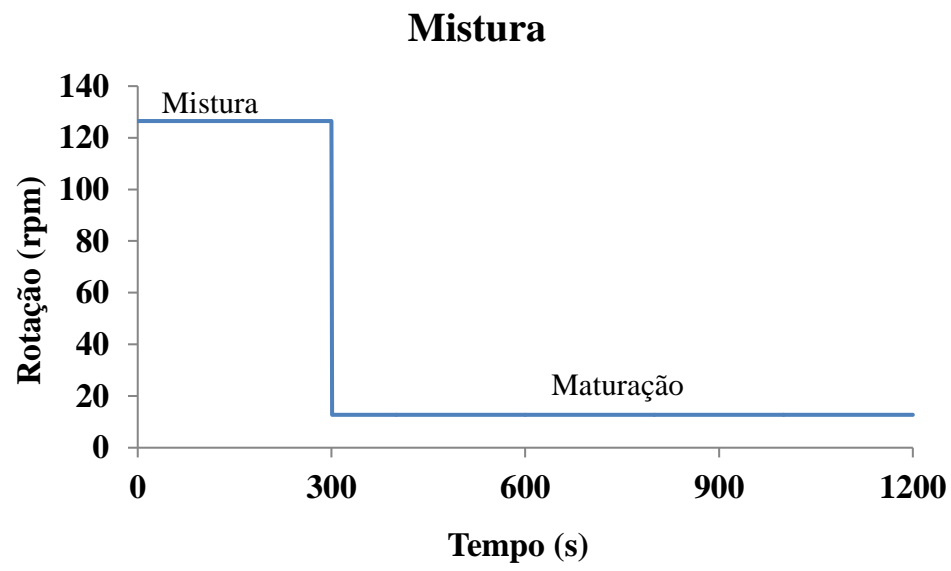

Figura 3 - Programa de rotações da reometria de mistura

\section{Ciclos de cisalhamento}

Para a análise do comportamento em relação ao ciclo de cisalhamento, depois da realização da mistura, foram aplicados dois ciclos completos com patamares de 6,$3 ; 12,7 ; 25,3 ; 38,0 ; 63,3$; 126,$5 ; 189,8 ; 253,0$ e 316,3 rpm, tendo permanência de $5 \mathrm{~s}$ em cada rotação, repouso de 10 min entre os ciclos, e determinação do teor de ar incorporado. A Figura 4 indica o ciclo de cisalhamento utilizado para a reometria rotacional.

\section{Resultados e discussões}

\section{Determinação do Teor de Fases (Volume)}

$\mathrm{O}$ teor de fases indica o volume de cada componente da argamassa. Neste caso, foi separado o volume do agregado, finos (partículas < $75 \mu \mathrm{m}$ da areia + aditivos + cimento), água e teor de ar incorporado, sendo este último determinado

130 Kudo, E. K.; Cardoso, F. A.; Pileggi, R. G. 
pela NBR 13278 (ABNT, 2005). As distribuições das argamassas ACI e ACIII estão representadas na Figura 5. Esses teores de fases foram obtidos após a mistura, e cada coluna do gráfico representa a argamassa, o teor de água e a fração da composição.
A Tabela 2 mostra os teores de ar incorporado, determinados após a mistura e ciclos de cisalhamento.

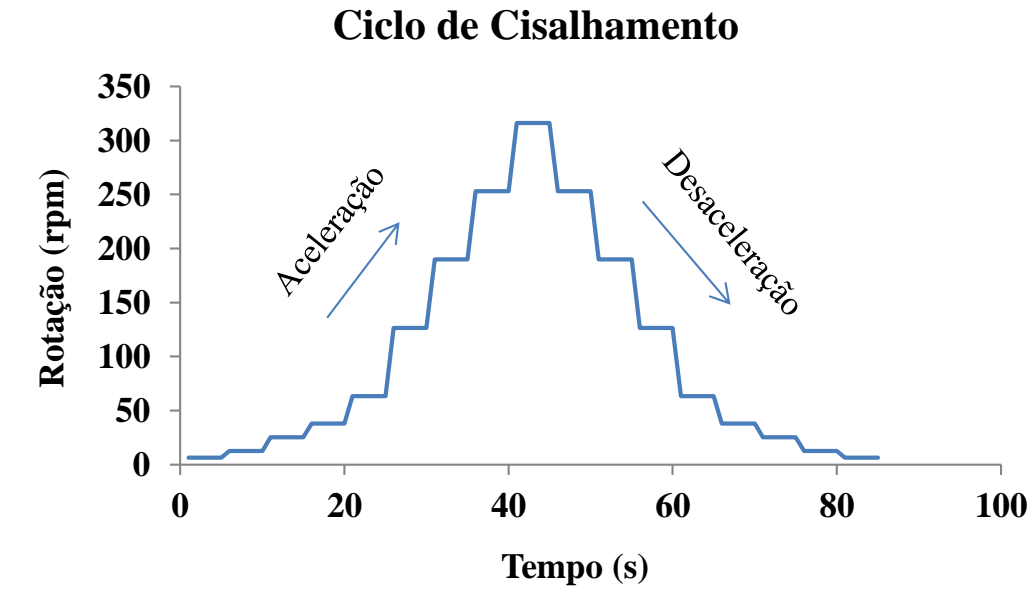

Figura 4 - Programa de rotações para avaliação dos ciclos de cisalhamento

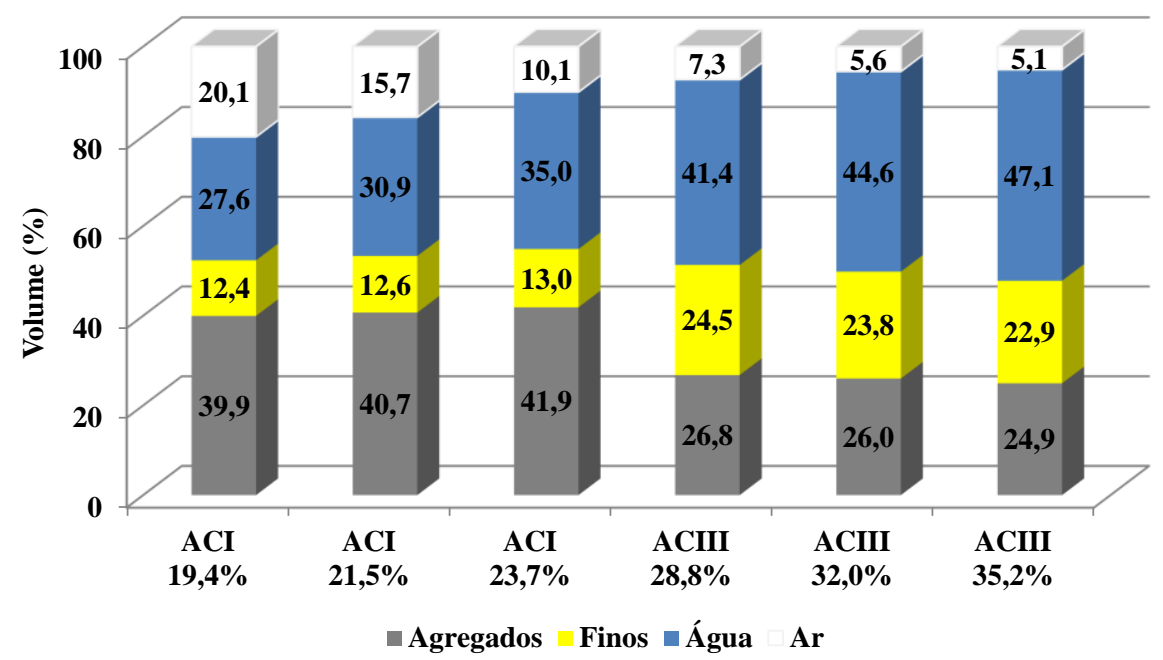

Figura 5 - Distribuição de fases das argamassas de mercado ACl e ACIII: agregados e pasta (finos + água + ar), após mistura

Tabela 2 - Teor de ar incorporado, determinado após a mistura e ciclos de cisalhamento, com os teores de água de $19,4 \%, 21,5 \%$ e $23,7 \%$ para $\mathrm{ACl}$ e de $28,8 \%, 32,0 \%$ e $35,2 \%$ para $\mathrm{ACIII}$, sendo o teor de água nominal de $21,5 \%$ para $\mathrm{ACl}$ e de $32,0 \%$ para ACIII

\begin{tabular}{c|c|c|c|c}
\hline \multirow{2}{*}{ Argamassa } & \multirow{2}{*}{$\begin{array}{c}\text { Teor de água } \\
(\boldsymbol{\%})\end{array}$} & \multicolumn{3}{|c}{ Teor de ar incorporado (\%) } \\
\cline { 3 - 5 } & 19,4 & Mistura & Ciclo 1 & Ciclo 2 \\
\hline \multirow{3}{*}{ ACI } & 21,5 & 20,1 & 19,6 & 20,1 \\
& 23,7 & 15,7 & 15,2 & 14,7 \\
& 28,8 & 7,1 & 10,1 & 10,1 \\
\hline \multirow{3}{*}{ ACIII } & 32,0 & 5,6 & 8,8 & 9,3 \\
& 35,2 & 5,1 & 6,1 & 6,6 \\
& & & 4,0 & 3,5 \\
\hline
\end{tabular}


Para as argamassas ACI e ACIII, quanto maior o teor de água, menor o teor de ar incorporado. Isso ocorreu devido à redução da viscosidade e à capacidade de estabilizar as bolhas que estavam na pasta. Com esta menor viscosidade, as bolhas têm mais mobilidade e podem migrar para a superfície ou colapsar.

A Tabela 2 mostra que, entre a mistura e os ciclos, ocorreram três comportamentos da argamassa em função dos ciclos de cisalhamento: constante, crescente e decrescente. Para a argamassa ACI utilizando o teor de água de $19,4 \%$, após a mistura, ocorreu uma ligeira queda do teor de ar incorporado no primeiro ciclo; depois, quando aplicado o segundo ciclo, o teor de ar se manteve igual ao obtido na mistura. Para o teor de água de $21,5 \%$, observou-se que ocorreu uma ligeira queda do teor de ar incorporado entre a mistura e os ciclos; e, por fim, para o teor de água de $23,7 \%$, observou-se que o teor de ar incorporado se manteve constante.

Para a argamassa ACIII nota-se que, para os teores de água de $28,8 \%$ e $32,0 \%$ entre a mistura e os ciclos, o teor de ar incorporado apresentou uma ligeira tendência de aumento; já para o teor de água de $35,2 \%$, observa-se que ocorreu o inverso, o teor de ar incorporado sofreu uma pequena tendência de queda. Entretanto, a experiência obtida através de cinco repetições feitas em laboratório indica que o erro do ensaio de determinação do teor de ar incorporado gira em torno de $1 \%$ em valor absoluto. Então, apesar de apresentarem essas variações, verifica-se que os valores obtidos estão dentro do erro do próprio ensaio.

\section{Comportamento de mistura}

A Figura 6 mostra os resultados do comportamento de mistura das argamassas ACI e ACIII.

Quando a água foi introduzida nas argamassas, primeiro ocorreu o aumento do nível de torque para a mistura. Em seguida, a curva atingiu o ponto de virada, em que ocorreram o torque máximo e a aglomeração do sistema (PILEGGI; STUDART; PANDOLFELLI, 2001). A partir deste ponto, deu-se início ao decaimento da curva, ocorrendo o decréscimo do valor de torque e a tendência à estabilização do sistema (curva constante).

Segundo Pileggi, Studart e Pandolfelli (2001), as forças de Van der Waals e as forças capilares, na presença de água, são as responsáveis pela coesão das partículas. No momento da introdução do líquido, quando da preparação de argamassas no processo de mistura, uma série de eventos ocorre no sistema, que, por sua vez, resultam em esforços durante esta etapa, gerando o nível de torque mais elevado.

Dessa forma, o método mostrou ser sensível para diferenciar o nível de torque resultante nas argamassas ACI e ACIII, sendo o torque resultante de virada na ACI superior aos torques resultantes na ACIII. Porém, o torque de estabilização entre as duas argamassas foi muito próximo quando utilizado o teor de água nominal do produto (21,5\% para ACI, e 32,0\% para ACIII).

Para a argamassa ACI, quando utilizado o teor de água de $19,4 \%$, os níveis de torque de mistura foram superiores, se comparados aos outros teores de água. Para a argamassa ACIII, a ação dos aditivos químicos é mais clara, pois a virada é mais rápida e ocorre a mudança do perfil da curva.

Para a argamassa ACIII, utilizando-se diferentes teores de água, a diferença entre os níveis de torque não foi intensa. Isso ocorreu devido à maior presença de finos (partículas $<75 \mu \mathrm{m}$ da areia + cimento) e também aos aditivos químicos utilizados, especialmente o celulósico, que eleva a viscosidade da pasta, reduzindo o efeito da variação do teor de água.

O principal efeito do éter de celulose (MHEC ou MHPC) no comportamento reológico de materiais cimentícios é a alteração da viscosidade da fase aquosa e a modificação dos fenômenos físicos devido a sua estrutura e capacidade de retenção de água. Já o efeito dos polímeros vinílicos ou acrílicos (EVA ou PVA) é tornar esses materiais mais fluidos, o que ocorre devido ao efeito de rolamento, proporcionado pelas partículas poliméricas, e à presença de ar incorporado, além da contribuição na dispersão das partículas devido ao tensoativo normalmente utilizado na produção desses polímeros (OHAMA, 1998; BETIOLI, 2007).

Considerando a tendência à estabilização do sistema após o decaimento da curva, o tempo necessário para que o nível de torque da mistura se estabilizasse e ficasse constante foi de aproximadamente $150 \mathrm{~s}$ nas argamassas ACI e ACIII com o teor de água nominal especificado pelo fabricante. Após esse período, o produto apresentou características de mistura estável, homogênea, fluida e sem material aglomerado. Apenas na argamassa ACI com o teor de água de $19,4 \%$ foi necessário mais tempo para a estabilização da mistura.

Na mistura manual, a percepção de mistura é a inversa, em que o ACIII apresenta maior energia de mistura e menor facilidade de homogeneização. 
Para a explicação desse comportamento são propostas duas hipóteses:

(e) a mistura mecânica impõe um cisalhamento intenso e rompe as partículas aglomeradas, liberando a água com maior rapidez, então a argamassa escoa com maior facilidade; ou

(f) a utilização de polímeros modificados (EVA/PVA), no momento da mistura com a água, faz com que as partículas não se aglomerem, devido à deposição do polímero sobre o grão do cimento, reduzindo a taxa de dissolução das fases anidras, isso somado ao efeito do surfactante, que aumentam a lubrificação e reduzem a viscosidade aparente (OHAMA, 1998), de forma que a argamassa escoe com maior facilidade mesmo com quantidade superior de pasta (finos + água + ar).

(a) $\quad 2,5$

ACI x ACIII

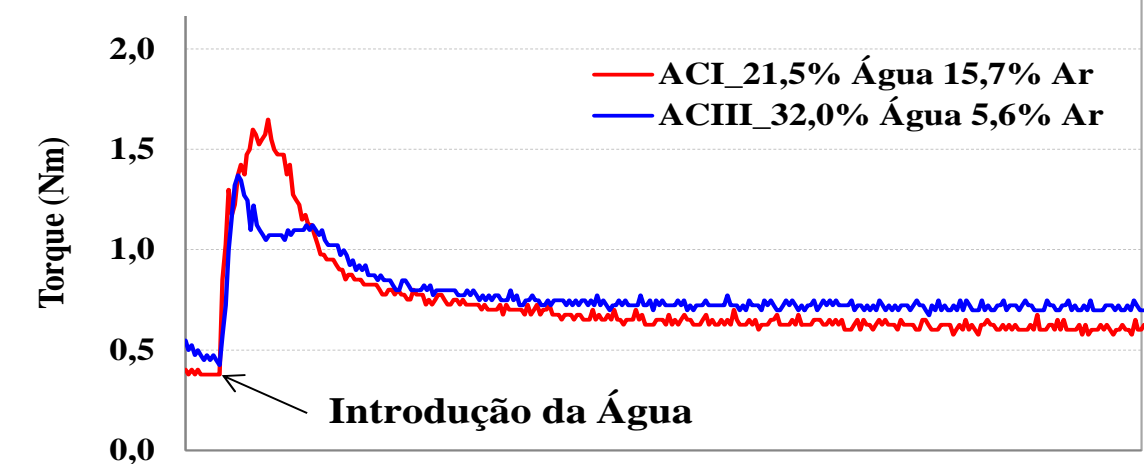

(b)
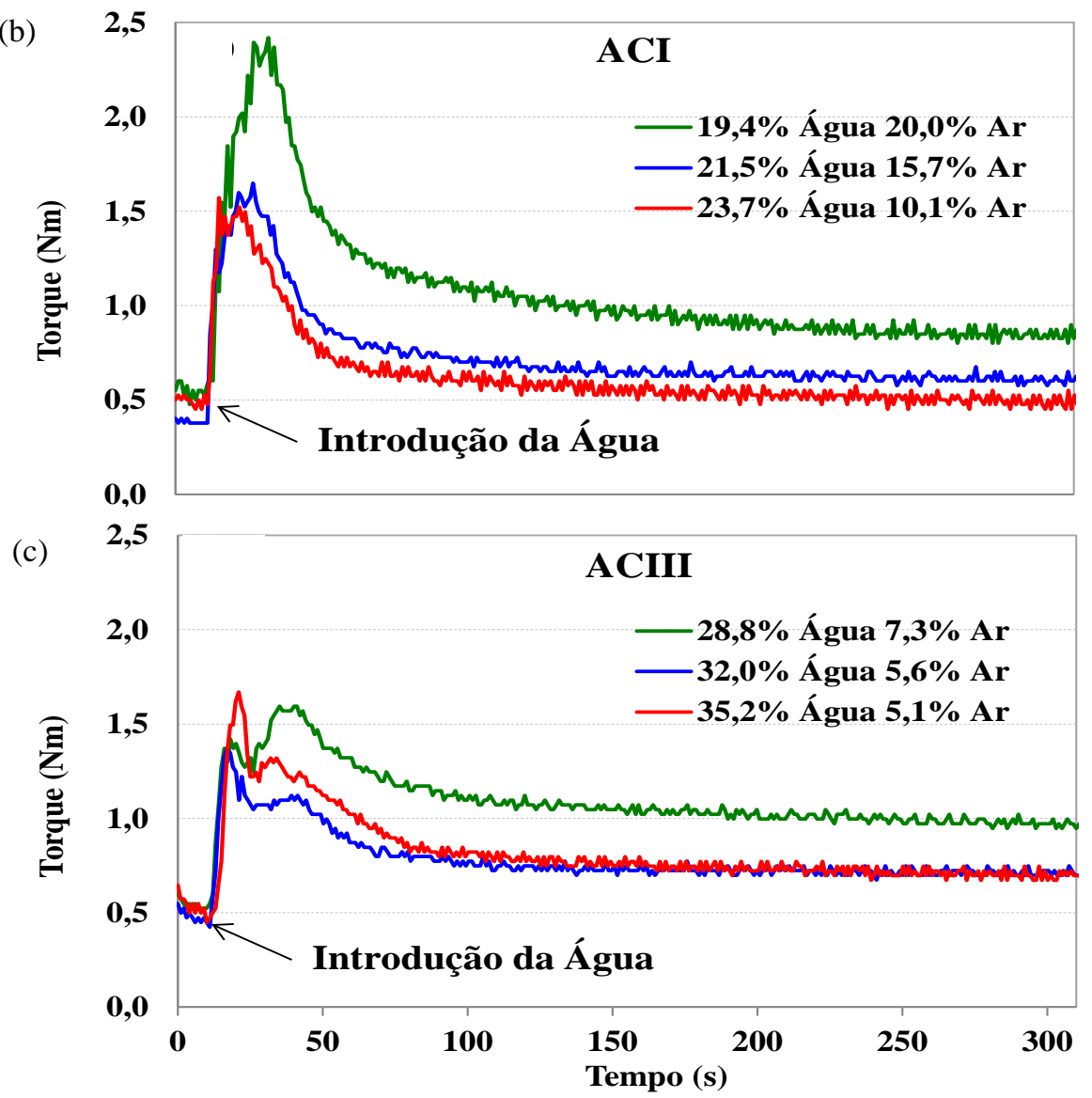

Figura 6 - (a) $\mathrm{ACl}$ submetida à mistura no reômetro, teor de água de $21,5 \%$ para $\mathrm{ACl}$ e de $32,0 \%$ para $\mathrm{ACIII}$; (b) $\mathrm{ACl}$ submetida à mistura no reômetro com diferentes teores de água, $19,4 \%, 21,5 \%$ e $23,7 \%$; e (c) ACIII submetida à mistura no reômetro com diferentes teores de água, $28,8 \%, 32,5 \%$ e $35,2 \%$ 


\section{Ciclos de cisalhamento}

Para a análise de histerese, os ciclos foram realizados duas vezes e não ocorreram diferenças significativas entre os ciclos, devido à eficiente dispersão da mistura realizada no primeiro ciclo. Devido à avaliação do produto em um intervalo inferior a $2 \mathrm{~h}$, não foram observadas mudanças significativas com o tempo.

Para ACI e ACIII, a mistura de 300 s em uma rotação de 126,5 rpm foi suficiente para produzir uma suspensão estável, fluida e homogênea, pois, quando os ciclos de cisalhamento foram aplicados, as áreas de histerese foram pequenas ou quase nulas. Segundo Schramm (2006), quando a rampa de subida é seguida imediatamente pela rampa de descida, a quebra total da estrutura pode não ocorrer, ou seja, o ciclo de cisalhamento ou a mistura não foram suficientes para quebrar toda a estrutura e homogeneizar a mistura, sendo necessária a aplicação de outros ciclos, até que as curvas se sobreponham, indicando que toda a estrutura foi destruída pelo cisalhamento, ou seja, a suspensão foi totalmente homogeneizada.
A análise a seguir levou em conta somente a curva de desaceleração do ciclo de cisalhamento, devido à característica citada anteriormente. A Figura 7 mostra os resultados das argamassas ACI e ACIII.

Para o teor de água de $19,4 \%$, na ACI, o torque de escoamento (energia para que o escoamento se inicie) foi superior em relação aos outros teores. Com este teor de água, a viscosidade é maior, o que indica a dificuldade de mobilidade das partículas.

A Tabela 3 mostra as equações das curvas obtidas para cada teor de água.

O cálculo da linha de tendência para a desaceleração indica a equação de regressão linear $\mathrm{y}=\mathrm{ax}+\mathrm{b}$, onde " $\mathrm{a}$ " equivale à viscosidade plástica $\mathrm{e}$ "b" ao torque inicial de escoamento. Essa equação indica que a argamassa ACI apresentou maior viscosidade e torque de escoamento, e mostrou ser mais sensível a diferentes teores de água quando aplicados os ciclos de cisalhamento em relação à argamassa ACIII.

A Figura 8 mostra o comparativo entre as curvas obtidas para ACI e ACIII.

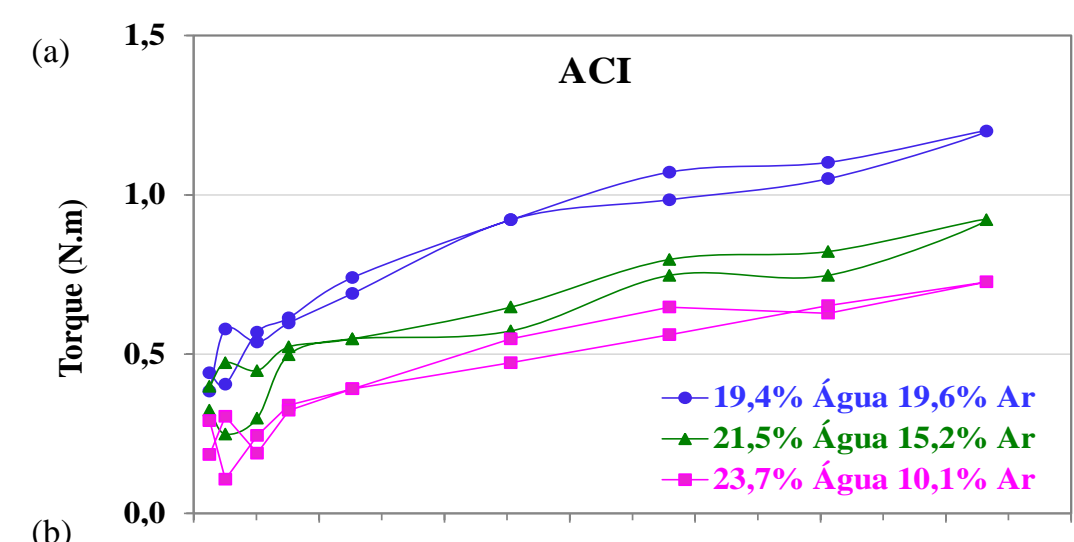

(b)

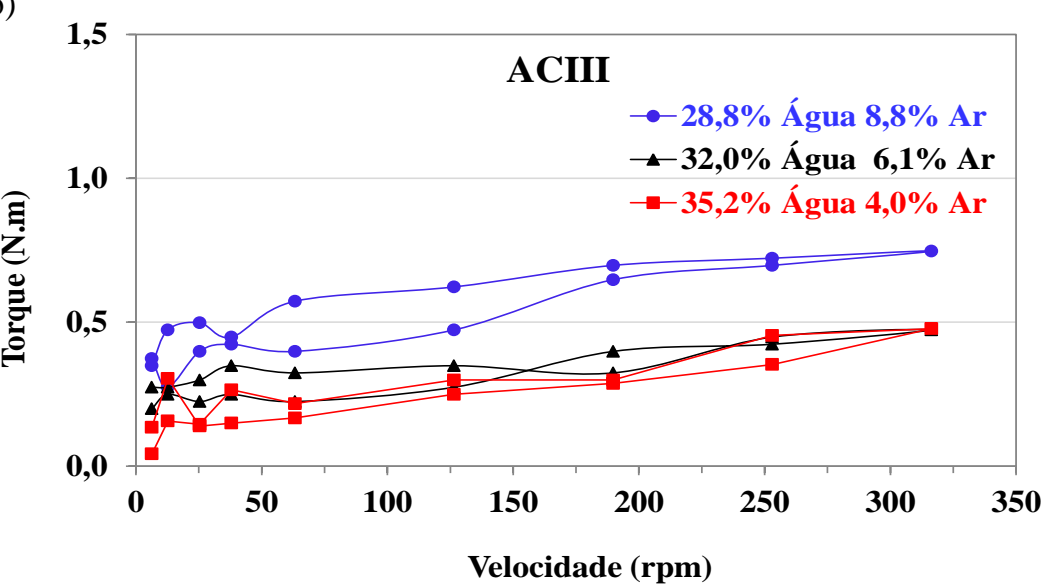

Figura 7 - Aplicação de ciclo de cisalhamento de 6,3 a 316,3 rpm com permanência de $5 \mathrm{~s}$ em cada rotação, em $\mathrm{ACl}$ (a) e ACIII (b) com teor de água de 19,4\%, 21,5\% e 23,7\% para $\mathrm{ACl}$ e de $28,8 \%, 32,0 \%$ e $35,2 \%$ para ACIII, sendo o teor de água nominal de $21,5 \%$ para $\mathrm{ACl}$ e de $32,0 \%$ para ACIII

134 Kudo, E. K.; Cardoso, F. A.; Pileggi, R. G. 
Tabela 3 - Equações das curvas de aplicação de faixa de taxa de cisalhamento, aplicada no teor de água de $19,4 \%, 21,5 \%$ e $23,7 \%$ para $\mathrm{ACl}$ e de $28,8 \%, 32,0 \%$ e $35,2 \%$ para $\mathrm{ACIII}$

\begin{tabular}{c|c|c}
\hline Argamassa & Teor de água e ar incorporado & Equação da reta \\
\hline \multirow{3}{*}{ ACI } & $19,4 \%$ água 19,6 ar & $\mathrm{y}=0,0023 \mathrm{x}+0,5048$ \\
& $21,5 \%$ água $15,2 \mathrm{ar}$ & $\mathrm{y}=0,0019 \mathrm{x}+0,3265$ \\
& 23,7 água $10,1 \mathrm{ar}$ & $\mathrm{y}=0,0016 \mathrm{x}+0,2340$ \\
\hline \multirow{3}{*}{ ACIII } & 28,8 água 8,8 ar & $\mathrm{y}=0,0014 \mathrm{x}+0,3335$ \\
& 32,0 água 6,1 ar & $\mathrm{y}=0,0009 \mathrm{x}+0,2030$ \\
& 35,2 água 4,0 ar & $\mathrm{y}=0,0009 \mathrm{x}+0,1506$ \\
\hline
\end{tabular}

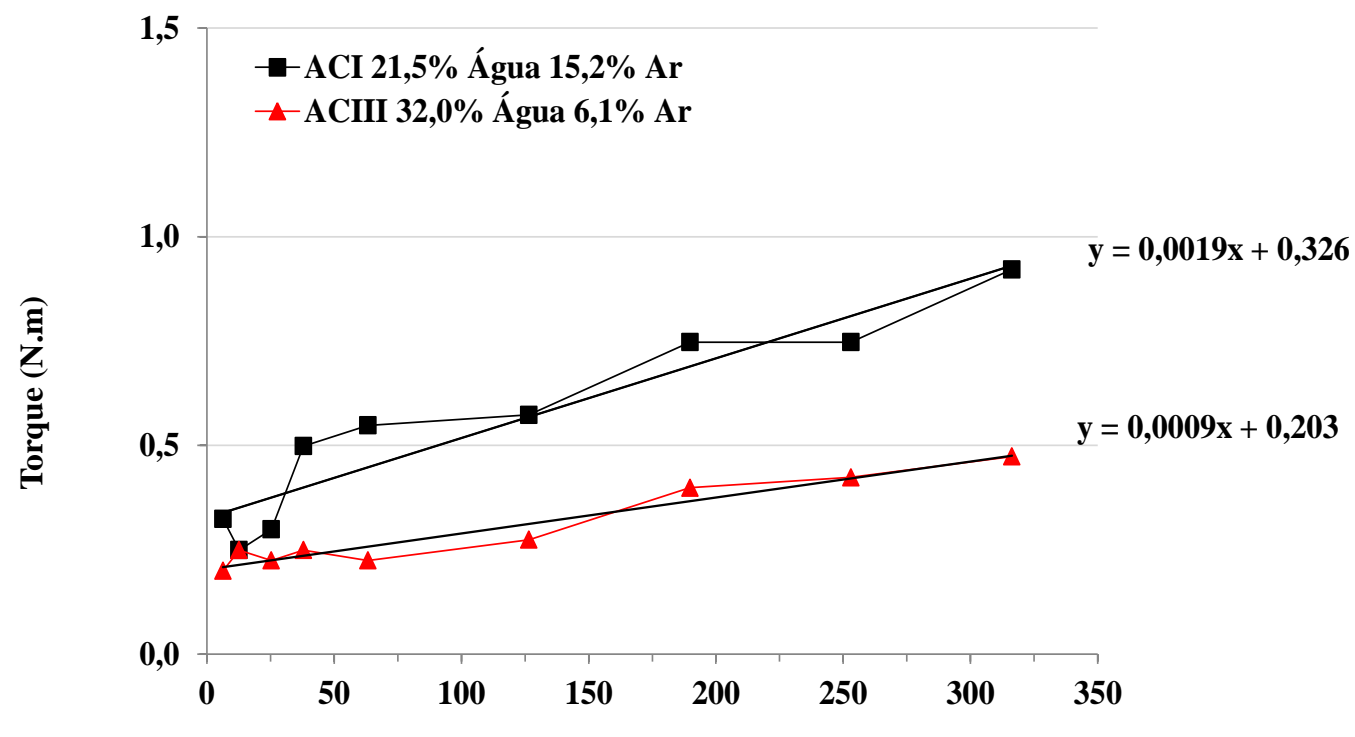

Velocidade (rpm)

Figura 8 - Aplicação de ciclo de cisalhamento de 6,3 a 316,3 rpm com permanência de $5 \mathrm{~s}$ em cada rotação, com teor de água de $21,5 \%$ para $\mathrm{ACl}$ e de $32,0 \%$ para $\mathrm{ACIII}$

A argamassa ACI apresentou níveis de torque superiores, quando comparada à ACIII, indicando ter maior viscosidade. Esse comportamento foi inverso ao percebido em campo: a percepção do aplicador é a de que a ACIII possui maior viscosidade do que a ACI.

Essa inversão de comportamento com a mistura mecânica pode ter ocorrido devido à composição da ACIII, a qual possui mais matriz (finos + água + ar) e aditivos químicos (polímero EVA), que melhoraram o rolamento das partículas na suspensão (BETIOLI, 2007), fazendo com que a mistura ficasse mais fluida, reduzindo o nível de torque.

Outro ponto observado e mencionado no item de mistura é a hipótese de a mistura realizada no reômetro aplicar mais cisalhamento e romper profundamente os aglomerados.

\section{Conclusões}

A reometria rotacional mostrou ser uma metodologia eficaz para o estudo do comportamento de mistura de argamassas colantes, eliminando, assim, a subjetividade da avaliação.

A argamassa ACI apresentou níveis de torque superiores, quando comparada à ACIII, indicando ter maior viscosidade. Esse comportamento foi inverso ao percebido em campo, onde a percepção do aplicador é a de que a ACIII possui maior viscosidade do que a ACI. Esta inversão de comportamento com a mistura mecânica pode ter origem mais provável na própria composição da ACIII, a qual possui mais matriz (finos + água + ar) e aditivos químicos (polímero EVA/PVA), que melhoraram $\mathrm{o}$ rolamento das partículas na suspensão, fazendo com que a mistura fique mais fluida, reduzindo o nível de torque. No entanto, este estudo necessita ser mais bem explorado para consolidar a investigação da origem da divergência entre a avaliação de campo e a mistura mecânica. 
O tempo de mistura de $150 \mathrm{~s}$ foi eficiente para homogeneizar e estabilizar as misturas das argamassas ACI e ACIII com o teor de água nominal do produto.

Para as argamassas ACI e ACIII, quanto maior o teor de água, menor é o teor de ar incorporado, o que ocorre devido à redução da viscosidade da pasta e à capacidade de estabilizar as bolhas que estão na pasta.

\section{Referências}

ANTUNES, R. P. N.; JOHN; V. M.; PILEGGI, R. G. Influência da Sequência de Mistura nas Propriedades Reológicas de Argamassas Avaliadas Por Squeeze-Flow. In: SIMPÓSIO BRASILEIRO DE TECNOLOGIA DAS ARGAMASSAS, 6 ., Florianópolis, 2005. Anais... Florianópolis, 2005.

ASSOCIAÇÃO BRASILEIRA DE NORMAS TÉCNICAS. NBR14081-1: argamassa colante industrializada para assentamento de placas cerâmicas: parte 1: requisitos. Rio de Janeiro, 2012.

\section{ASSOCIAÇÃO BRASILEIRA DE NORMAS} TÉCNICAS. NBR 13278: argamassa para assentamento e revestimento de paredes e tetos: determinação da densidade de massa e do teor de ar incorporado. Rio de Janeiro, 2005.

BARNES, H. A. The Yield Stress a review or everything flows. Construction and Building Materials, v. 81, n. 1/2, p. 133-178, mar. 1998.

BANFILL P. F. G.; SAUNDERS D. C. On the Viscometric Examination of Cement Pastes. Cement and Concrete Research, v. 11, n. 3, p. 363-370, maio 1981.

BETIOLI, A. Influência dos Polímeros MHEC e EVA na Consolidação de Pastas Cimentícias. 190 f. Florianópolis, 2007. Tese (Doutorado em Engenharia Civil) - Escola de Engenharia, Universidade Federal de Santa Catarina, Florianópolis, 2007.

CARDOSO, F. A. Método de Formulação de Argamassas de Revestimento Baseado em Distribuição Granulométrica e Comportamento Reológico. 158 f. São Paulo, 2009. Tese (Doutorado em Engenharia Civil) - Escola Politécnica, Universidade de São Paulo, São Paulo, 2009.

COLLIN, V.; JÉZÉQUEL P. H. Mixing of Concrete or Mortars: distributive aspects. Cement and Concrete Research, v. 39, n. 8, p. 678-686, 2009.
FRANÇA, M.; CARDOSO, F.; PILEGGI, R. Influência do Tempo de Mistura nas Propriedades Reológicas de Argamassas. In: SIMPÓSIO BRASILEIRO DE TECNOLOGIA DE ARGAMASSAS, 9., Belo Horizonte, 2011. Anais... Belo Horizonte, 2011.

MALKIN, A. Y. Rheology Fundamentals. Ontario, CA: ChemTec, 1994.

OHAMA, Y. Polymer-Based Admixtures. Journal Cement and Concrete Composites, v. 20, n. 2/3, p. 189-212, 1998.

OLIVEIRA, I. R. et al. Dispersão e Empacotamento de Partículas: princípios e aplicações em processamento cerâmico. São Paulo: Fazendo Arte, 2000. 224 p.

PATURAL, L. et al. Cellulose Ethers Influence on Water Retention and Consistency in CementBased Mortars. Cement and Concrete Research, v. 41, n. 1, p. 46-55, 2010.

PILEGGI, R. G.; STUDART, A. R.;

PANDOLFELLI, V. C. How Mixing Affects the Rheology of Refractory Castables: part 1, part2. American Ceramic Society Bulletin, v. 80, n. 6, p. 27-42, 2001.

PÓVOAS, Y. V. Avaliação da Formação de "Película" na Argamassa Colante e Sua Influência na Adesão. 159 f. São Paulo, 2005. Tese (Doutorado em Engenharia Civil) - Escola Politécnica, Universidade de São Paulo, São Paulo, 2005.

ROMANO, R. C. O. et al. Impacto do Uso de Incorporador de Ar nas Propriedades Reológicas de Argamassas. In: SIMPÓSIO BRASILEIRO DE TECNOLOGIA DE ARGAMASSAS, 7., Recife, 2007. Anais... Recife, 2007.

SCHRAMM, G. Reologia e Reometria: fundamentos teóricos e práticos. São Paulo: Artliber, 2006. 232 p.

STEFFE, J. F. Rheological Methods in Food Process Engineering. $2^{\text {nd }}$. East Lansing: Freeman, 1996. 428 p.

VAN DEN BRULE, B. H. A. A.; KADIJK, S. E. A Simple Constant-Stress Rheometer. Journal of Non-Newtonian Fluid Mechanics, v. 43, p. 127139, 1992.

WINTHER, G.; LARSSON, I.; KRAMER, O. A Non-Rotational Universal Rheometer: part II: experimental procedures and results. Journal of Polymer Testing, v. 10, p. 263-277, 1991. 


\section{Agradecimentos}

À Weber Saint Gobain e ao Dr. Paul Houang, pelo apoio ao trabalho.

Revista Ambiente Construído Associação Nacional de Tecnologia do Ambiente Construído Av. Osvaldo Aranha, $99-3^{\circ}$ andar, Centro Porto Alegre - RS - Brasil CEP $90035-190$

Telefone: +55 (51) 3308-4084

Fax: +55 (51) 3308-4054

www.seer.ufrgs.br/ambienteconstruido

E-mail: ambienteconstruido@ufrgs.br 